\title{
REVIEW
}

\section{Selective Recruitment of Monocyte Subsets by Endothelial N-Glycans}

\author{
Kellie Regal-McDonald ${ }^{\star \dagger}$ and Rakesh P. Patel ${ }^{* \dagger}$
}

From the Department of Pathology* and the Center for Free Radical Biology ${ }^{\dagger}$, University of Alabama at Birmingham, Birmingham, Alabama

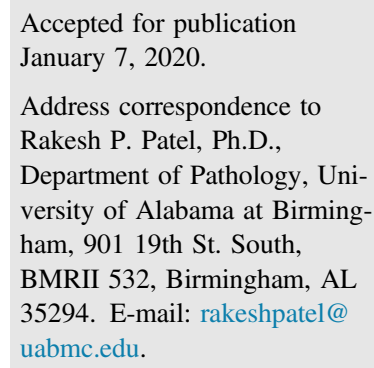

The endothelium, via a myriad of mechanisms, orchestrates vascular homeostasis to maintain a healthy luminal surface. Perturbation of these mechanisms, as occurs by chronic exposure of the endothelial cell layer to hyperlipidemia, hyperglycemia, pro-oxidant and inflammatory stimuli, or turbulent blood flow, results in endothelial dysfunction. The latter is an established feature of vascular inflammatory disease, including atherosclerosis, a chronic disease that leads to the buildup of fat-filled plaques in the vessel wall. ${ }^{1-3} \mathrm{~A}$ dysfunctional endothelium is characterized by various biochemical, morphologic, molecular, and functional changes. Cardinal among these is a more adhesive endothelial surface, which, in turn, is key to the recruitment and extravasation of monocytes into the subendothelial space. ${ }^{2}$ Circulating monocytes are captured onto the endothelium via a process of rolling, firm adhesion, and ultimately migration through the endothelium to the intima, after which they can differentiate into macrophages and form fatty plaque formation.
Specific binding between adhesion molecules expressed on the surface of the leukocyte and endothelium is the established mechanism by which monocytes roll, adhere, and transmigrate across the endothelium. These adhesion molecules, their respective cognate receptors, and their roles in the adhesion cascade are known and how their function is controlled is also largely understood. On the endothelial side, the most appreciated mechanism involves regulation of surface adhesion molecule expression levels. Proinflammatory stimuli induce signaling cascades, typically via $\mathrm{NF}-\kappa \mathrm{B}$, that either up-regulate gene, protein, and then surface expression, and/or mobilize preformed intracellular stores of adhesion molecules to the cell surface, where they can interact with circulating leukocytes. ${ }^{4,5}$ Strategies that target and inhibit endothelial adhesion molecule function, although effective in cell and preclinical models, have not

Supported by NIH T32 fellowship HL007918 (K.R.-M.).

Disclosures: None declared. 
translated to the clinic. ${ }^{6}$ Furthermore, much of our knowledge of endothelial adhesion molecule function, and how they bind with their cognate receptors on the monocyte, was elucidated at a time when both monocyte and vascular endothelial heterogeneity were not as appreciated as they are now. For example, monocytes exist in at least three distinct subtypes, each with varying functions in disease pathogenesis. ${ }^{7,8}$ Moreover, the mechanisms governing endothelial responses to inflammation vary, depending on the vascular bed in which these cells reside. ${ }^{1,9}$ These newer insights collectively highlight, in our opinion, a poorly understood aspect of monocyte-endothelial interactions (namely, are there different mechanisms that regulate how different monocyte subsets adhere to the endothelium, and in a manner that allows vascular bed and/or disease selectivity?). If so, how do these mechanisms change during the transition from innate immune responses to inflammatory disease?

This review discusses the concept of an endothelial zip code (ie, that there are molecular and/or biochemical signatures across vascular beds that control the homing of monocyte subsets to specific endothelial surfaces). ${ }^{1,9,10}$ This discussion is focused on endothelial adhesion molecule $\mathrm{N}$ glycosylation, a post-translational modification that remains a relatively underexplored facet of the mechanisms regulating adhesion molecule function. Studies have shown that $\mathrm{N}$-glycosylation of these proteins is a regulated process during inflammation, with this regulation varying depending on the vascular bed of origin or disease process (eg, cardiovascular, metabolic, or cancer). ${ }^{11,12}$ Regulation in this context does not refer to the binary, presence or absence of $\mathrm{N}$-glycosylation per se, as is the case with other posttranslational modifications (eg, phosphorylation), but instead refers to the changing composition of sugars within the N-glycan structure. Within this framework, we discuss the current understanding, hypotheses, and questions regarding how inflammation regulates endothelial $\mathrm{N}$-glycosylation, giving rise to different $\mathrm{N}$-glycoforms of the same adhesion molecule(s), and subsequently an endothelial $\mathrm{N}$-glycan zip code that is critical to selective recruitment of monocyte subsets. This review also discusses how specific adhesion molecule $\mathrm{N}$-glycoforms may offer new targets to therapeutically modulate monocyteendothelial interactions in inflammatory disease, but not innate immune processes.

\section{Monocytes Are Not All Created Equal}

Monocytes are myeloid-derived cells integral to the innate immune system and make up 5\% to $10 \%$ of total circulating leukocytes in healthy adults. Once mature and released from the bone marrow, they circulate for several days before undergoing cell death or infiltrating injured tissues, where they differentiate into macrophages and dendritic cells to resolve inflammation. ${ }^{13}$ Human monocytes are categorized into three different subsets based on surface expression of the lipopolysaccharide receptor $\mathrm{CD} 14$ and the $\mathrm{Fc} \gamma$ receptor III CD16. In healthy adults, approximately $90 \%$ of circulating human monocytes are classical monocytes $\left(\mathrm{CD} 14^{++} /\right.$ $\mathrm{CD} 16^{-}$) with the remaining approximately $10 \%$ comprising nonclassical $\left(\mathrm{CD} 14^{+} / \mathrm{CD} 16^{++}\right)$and intermediate $\left(\mathrm{CD} 14^{++} /\right.$ $\mathrm{CD} 16^{+}$) monocytes. ${ }^{7,14}$

Of the three subsets, classical monocytes are considered anti-inflammatory due to having the highest production levels of IL-10. ${ }^{15}$ They have high expression of genes encoding phagocytic, antimicrobial, and wound healing activities, highlighting their importance in tissue repair. ${ }^{16-18}$ Nonclassical monocytes express genes associated with cytoskeletal rearrangement, allowing for their patrolling behavior along the endothelium to survey tissues. ${ }^{19,20}$ They also have little secretory activity, only triggered by viruses or nucleic acids. ${ }^{16}$ Intermediate monocytes fall on a middle ground between the classical and nonclassical types. They have the greatest inflammatory potential and are the greatest producers of reactive oxygen species, for example. ${ }^{16,18,21,22}$ They harbor the highest expression of major histocompatibility complex-II (human leukocyte antigen-DR), which, in turn, gives them a strong capability of inducing $\mathrm{CD} 4^{+} \mathrm{T}$-cell proliferation. ${ }^{15,20}$ In contrast, some studies have demonstrated that intermediate monocytes are robust producers of the anti-inflammatory cytokine, IL- $10 .^{23,24}$ This speaks to the true intermediate nature of these monocytes; however, in the context of disease, it seems that the proinflammatory function of intermediate monocytes dominates any antiinflammatory capabilities, as will be discussed further in this review.

\section{Monocyte Subsets in Cardiovascular Disease}

Monocytes are key contributors to atherosclerotic plaque development, as they differentiate into macrophages in the intima that provide foci for foam cell formation. ${ }^{25,26}$ As monocytes contribute to both initial lesion formation and lesion advancement, ${ }^{27-31}$ understanding the dynamics of monocyte adhesion to endothelial cells remains an important question in understanding the proinflammatory mechanisms underlying atherogenesis.

Specific monocyte subsets are associated with distinct stages and disease outcomes. Multiple studies have demonstrated that circulating intermediate monocytes correlate with more advanced atherosclerosis and peripheral artery disease, and independently predict adverse cardiac events in at-risk patients. ${ }^{21,32-36}$ Results from the HOM SWEET $\mathrm{HOMe}^{32}$ and the CARE FOR $\mathrm{HOMe}^{37}$ studies show positive correlations between the levels of intermediate monocyte subsets with disease severity, prevalence of adverse cardiac events, and cardiac-related mortality in patients at risk for cardiovascular disease and in chronic kidney disease patients. In both of these studies, large cohorts of patients at increased cardiovascular risk were followed up for 3 to 4 years, and after adjustments for confounders, both 
studies found that intermediate monocytes were the only subset to independently correlate with cardiovascular events in these at-risk patient populations. ${ }^{32,34,37}$ These data may be explained by selective recruitment of nonclassical/intermediate $\mathrm{CD}_{16}{ }^{+}$monocytes, over classical $\mathrm{CD} 16^{-}$monocytes, to inflamed endothelial cells. An important consideration in understanding how monocytes adhere is their relative cell numbers; greater numbers increase probability of adhesion by the law of mass action. Indeed, in atherosclerosis, total monocyte numbers are increased, but relative distribution between classical and nonclassical is shifted; $\mathrm{CD} 16^{+}$monocytes can expand to approximately $20 \%$ to $30 \%$ of the total monocyte population, whereas $\mathrm{CD} 16^{-}$monocyte levels can decrease to approximately $70 \%$ to $80 \% .^{32,34,38-40}$ In addition to cell number, the affinity and avidity of adhesive interactions also regulate how different monocyte subsets bind to the endothelium. Supporting this concept are experiments that demonstrate, on a per cell basis, $\mathrm{CD} 16^{+}$monocyte adherence to tumor necrosis factor (TNF)- $\alpha$ stimulated endothelial cells is stronger compared with $\mathrm{CD} 16^{-}$monocytes. ${ }^{41-43}$ However, the mechanism(s) regulating $\mathrm{CD}^{+} 6^{+}$versus $\mathrm{CD}^{-} 6^{-}$adhesion remain(s) unclear.

\section{Models of Leukocyte Adhesion}

The endothelial adhesion molecules and their cognate leukocyte receptors that mediate adhesion have been identified $^{4-50}$ (Table 1). Broadly speaking, there are four models by which interactions between these receptors are regulated. The specific mechanisms vary by the tissue, leukocyte type, and disease; however; the general paradigms remain similar. ${ }^{51}$ These models include i) leukocyte cell number, ii) platelet bridging and chemokine-based recruitment, iii) receptor density (or amount per cell) and location on the cell surface, and iv) binding affinity and avidity between cognate receptors ${ }^{51-56}$ (Figure 1). Selected examples underlining these models include lymphocyte function-associated antigen 1 (LFA-1), which can exist in conformation-dependent low-, intermediate-, or highaffinity states that correlate with binding affinity to intercellular adhesion molecule 1 (ICAM-1); the high-affinity state increases binding to ICAM-1 by approximately 10,000-fold compared with the low-affinity state. ${ }^{57}$ Another well-characterized example is leukocyte P-selectin glycoprotein ligand-1 and its post-translational modification with sialyl-Lewis $\mathrm{X}$ sugars that provide the actual ligands for endothelial E-selectins or P-selectins; blocking the sialyl-Lewis X structure alone, without changing P-selectin glycoprotein ligand-1 expression, is sufficient to attenuate adhesion. ${ }^{58-60}$

How these models apply to the mechanisms controlling how different monocyte subsets adhere to endothelial cells remains unclear. This is an interesting question, especially because both $\mathrm{CD} 16^{-}$and $\mathrm{CD} 16^{+}$monocytes express similar ligands for endothelial adhesion molecules. Comparison of receptor expression between monocyte subsets isolated from healthy volunteers shows that that nonclassic monocytes express the lowest levels of CD11b, whereas intermediate and classical monocytes express higher and similar levels. ${ }^{7,20}$ Circulating monocytes isolated from cardiovascular disease patients show that all three subsets express similar levels of $\mathrm{CD} 11 \mathrm{~b},{ }^{33}$ suggesting receptor density per cell changes with disease. Recent studies show that, using the same cell number, adhesion of $\mathrm{CD} 16^{+}$and $\mathrm{CD} 16^{-}$ monocytes to TNF- $\alpha$-treated endothelial cells is similar. ${ }^{43}$ This suggests that adhesion of $\mathrm{CD}_{1} 6^{+}$versus $\mathrm{CD} 16^{-}$ monocytes would be largely proportional to their relative cell numbers. Although this is clearly important, CD16 monocytes comprise more of the total monocytes in disease, for example; this does not appear to be the sole mechanism regulating adhesion. For example, $\mathrm{CD} 16^{+}$monocyte adhesion to TNF- $\alpha$-treated endothelial cells decreased only approximately twofold to threefold, despite lowering their cell numbers by 10 -fold relative to $\mathrm{CD} 16^{-}$monocytes to model physiological ratios. ${ }^{43}$ Moreover, a mechanism for regulating monocyte subset adhesion based solely on relative cell number would not allow for fine control over the timing and location of where each monocyte adheres. Recent data, discussed below, extend the models outlined in Figure 1 and demonstrate that N-glycosylation of endothelial adhesion molecules regulates which monocyte subset they interact with.

\section{Sweetening Proteins by N-Glycosylation}

There are two major types of protein glycosylation: $\mathrm{N}$ linked and $\mathrm{O}$ linked. O-glycosylation involves adding galactose, N-acetylglucosamine (GlcNAc), and N-acetylgalactosamine (GalNAc) structures to serine and

Table 1 Major Endothelial Adhesion Molecules and Cognate Monocyte Receptors for Cell Rolling, Adhesion, and Transmigration

\begin{tabular}{ll}
\hline Endothelial adhesion molecule & Monocyte receptor \\
\hline Intercellular adhesion molecule 1 & Lymphocyte function-associated antigen 1 \\
& Macrophage-1 antigen \\
Vascular cell adhesion molecule 1 & Very late antigen-4 \\
Platelet endothelial cell adhesion molecule & Platelet endothelial cell adhesion molecule \\
Mucosal addressin cell adhesion molecule 1 & Integrin $\alpha 4 \beta 7$ \\
E-selectin and P-selectin & P-selectin glycoprotein ligand-1 \\
\hline
\end{tabular}


A
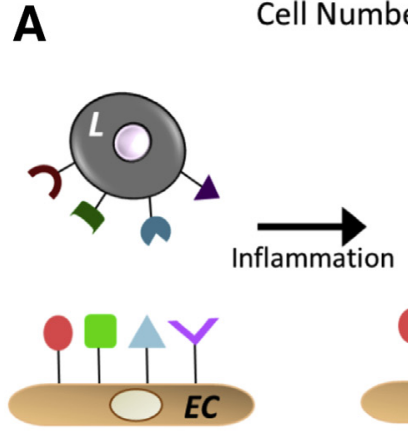

C

Receptor Density

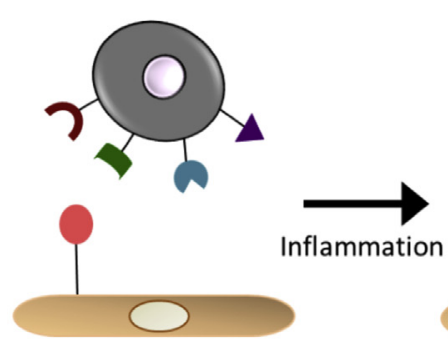

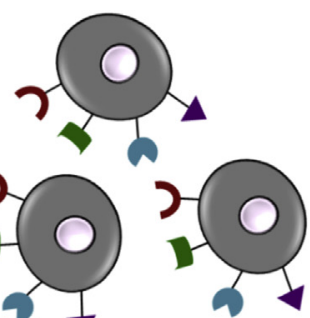
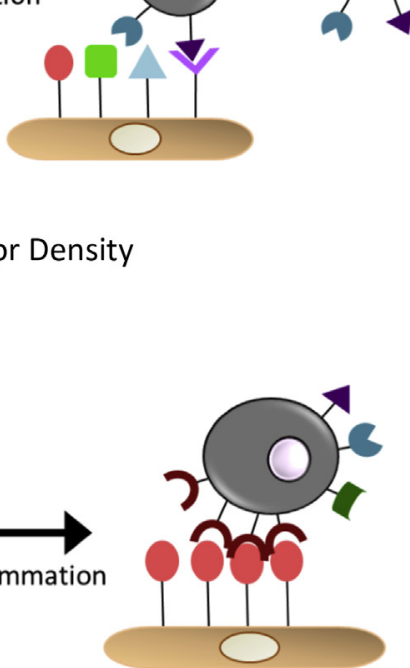

B
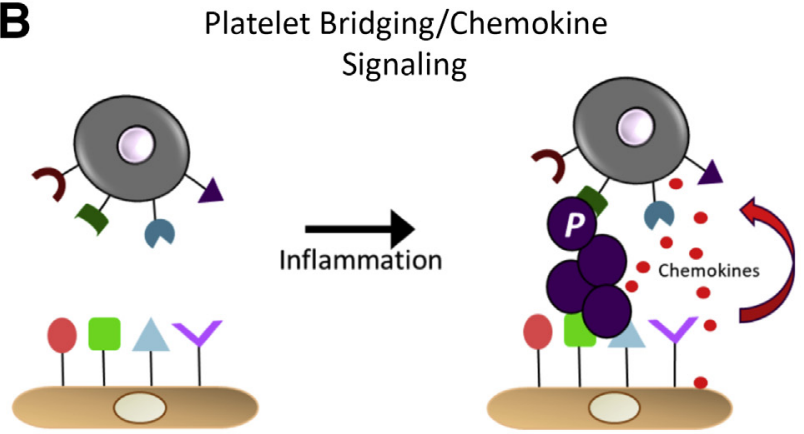

D

Clustering

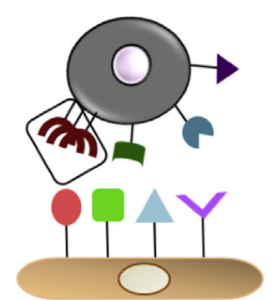

Ligand Affinity
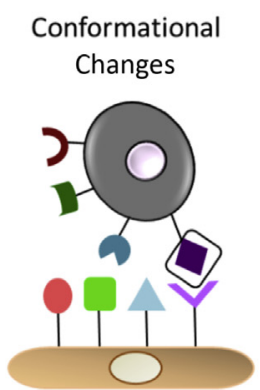

Post-Translational Modifications

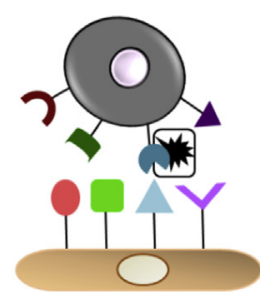

Figure 1 General mechanisms that regulate leukocyte (L)-endothelial interactions. A: An increase in cell number will increase the probability of binding via the laws of mass action. B: Platelet $(P)$ bridging and chemokine secretion by the endothelium to recruit leukocytes. Circulating platelets can adhere to the activated endothelium and either release chemokines that will recruit leukocytes to the cell or physically form a bridge and capture circulating leukocytes. Furthermore, damaged endothelial cells (ECs) can release chemokines to recruit leukocytes, and leukocytes crawling along the endothelium can also release chemokines that will recruit more leukocytes. ${ }^{55}$ C: Receptor density. During inflammation, either leukocyte or endothelial ligands on the cell surface that facilitate binding may increase. D: Potential mechanisms that regulate affinity and avidity for binding between adhesion molecules. These include posttranslational modifications, change in receptor confirmation, localization on the cell surface, and/or binding and clustering with other surface, cytosolic, or matrix proteins.

threonine residues of proteins. ${ }^{61,62}$ The focus herein will be on $\mathrm{N}$-glycosylation, which is a cotranslational or posttranslational modification occurring in the endoplasmic reticulum and Golgi. N-glycosylation only occurs on proteins expressed on the cell surface or secreted from the cell and involves the addition of a tetradecasaccharide onto asparagine (Asn) residues within the consensus sequence $(\mathrm{N}-\mathrm{X}-\mathrm{S} / \mathrm{T}$, where $\mathrm{X} \neq \mathrm{Pro}) .{ }^{63}$ During processing through the endoplasmic reticulum and Golgi, this tetradecasaccharide is remodeled, resulting in the sequential formation of high mannose (HM), hybrid, and then finally fully processed complex N-glycoforms. The latter can be large, significantly increasing the molecular weight of proteins and endowing tremendous structural diversity. Figure 2 shows the broad classifications and general structures of these $\mathrm{N}$-glycans, with the enzymes that catalyze the multistep process listed. ${ }^{63}$

$\mathrm{N}$-glycosylation is essential for proper protein folding, transport to the cell surface, function, and cell-to-cell communication. It is generally thought that proteins undergoing N-glycosylation will not be expressed on the cell surface unless they are fully processed to the complex form. Hypoglycosylated proteins fail quality check mechanisms in the endoplasmic reticulum, resulting in degradation and recycling. ${ }^{64,65}$ However, recent evidence suggests that proteins harboring hypoglycosylated (ie, $\mathrm{HM}$ or hybrid) $\mathrm{N}$-glycans can, in fact, be expressed on the cell surface or secreted from the cell, as part of normal cell functions. ${ }^{66,67}$ For example, the stress-independent activation of the transcription factor $X B P 1$, a marker of the unfolded protein response, increases surface $\mathrm{HM} \mathrm{N}$ glycans in HEK293 and HeLa cells by altering the transcript levels of key N-glycan processing genes, demonstrating a mechanism in which transcription factor activation alters the $\mathrm{N}$-glycome without requiring changing expression of the proteins harboring the $\mathrm{N}$-glycans. ${ }^{66}$ Furthermore, hypoglycosylated $\mathrm{N}$-glycoprotein expression may change in the inflamed endothelium (discussed below), ${ }^{66,68,69}$ and in diseases like cancer and lupus. ${ }^{12,70-73}$ Therefore, there may in fact be mechanisms that during inflammation regulate adhesion molecule $\mathrm{N}$ glycosylation, presumably to mediate specific functions. ${ }^{66}$ However, the precise nature of these hypoglycosylated $\mathrm{N}$-glycans, the proteins on which they reside, and the understanding of how they regulate protein function in physiology and the transition to pathology remain limited. 


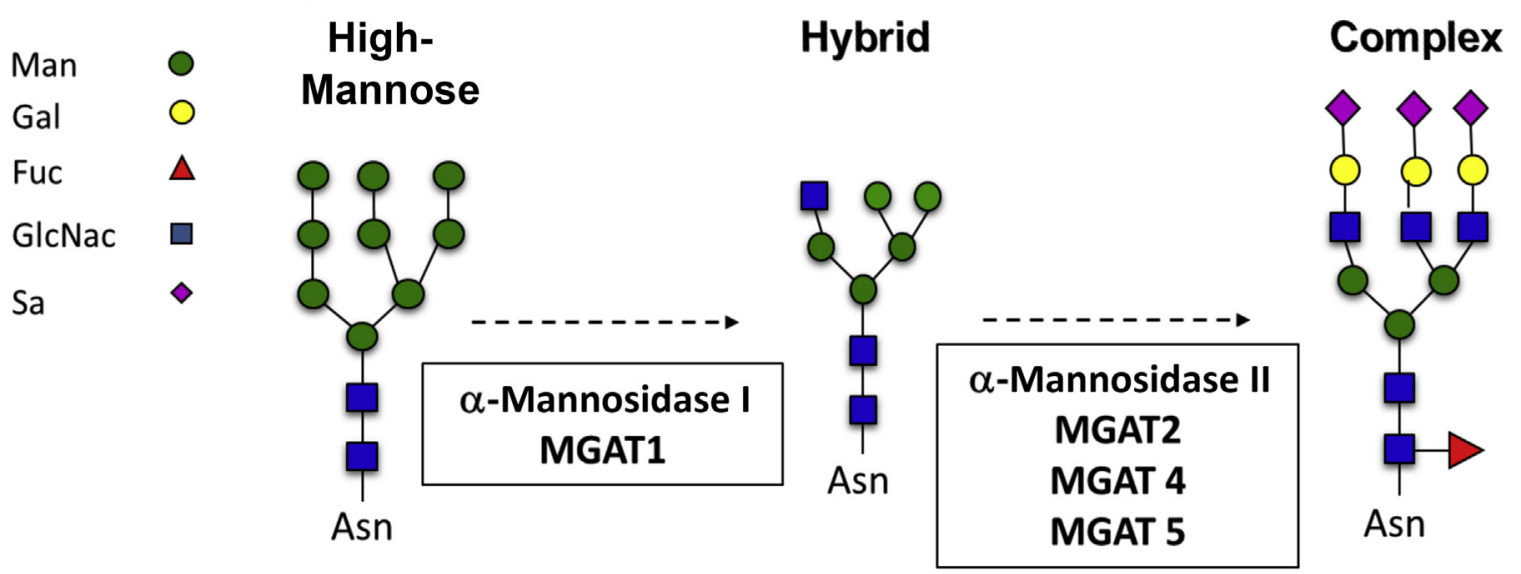

Figure 2 Broad classification of N-glycan structures. A tetradecasaccharide is initially added to Asn by oligosaccharide transferase (not shown). Further processing of this structure in the endoplasmic reticulum and Golgi involves catalytic removal and addition of sugars, resulting in the sequential formation of high mannose (Man), hybrid, and then complex N-glycans. Multiple steps are represented by dashed arrows, with enzymes catalyzing these processes listed below. Fuc, fucose; Gal, galactose; GlcNac, N-acetylglucosamine; MGAT, alpha-1,3-mannosyl-glycoprotein 2-beta-N-acetylglucosaminyltransferase; Sa, sialic acid.

\section{ICAM-1 N-Glycosylation and Monocyte Adhesion}

Endothelial adhesion molecules are extensively N-glycosylated. For example, ICAM-1, which is expressed at low levels constitutively and rapidly induced by proinflammatory stimuli, contains five extracellular IgG-like domains and, based on amino acid composition, has a predicted molecular weight of approximately $50 \mathrm{kDa}$. However, ICAM-1 runs at approximately $100 \mathrm{kDa}$ on an immunoblot, and the 50-kDa protein is only observed if all of the N-glycans are cleaved by PNGase-F, a glycosidase that will cleave $\mathrm{N}$-glycans from the Asn residue, or if addition of the initial tetradecassacharide is inhibited by tunicamycin. ${ }^{68}$ Induced ICAM-1 can also run as a $75-\mathrm{kDa}$ band, which is less abundant than the 100-kDa band, and often overlooked or ignored. ${ }^{74-76}$ This $75-\mathrm{kDa}$ band is, in fact, an HM N-glycoform of ICAM-1. ${ }^{68}$ Western blot analysis showed two distinct molecular weight bands for ICAM-1 in endothelial cells treated with TNF- $\alpha$ (Figure 3A). Inhibiting $\alpha$-mannosidase I leads to an accumulation of HM N-glycans; ICAM-1 is expressed as the 75-kDa form (Figure 2). In this case, ICAM-1 still contains $\mathrm{N}$-glycans; hence, the molecular weight is $>50 \mathrm{kDa}$, but not to the extent of sugars present in the $100-\mathrm{kDa} \mathrm{N}$-glycoform. Additional data supporting identification of the 75$\mathrm{kDa}$ band as an $\mathrm{HM}$ glycoform of ICAM-1 includes endoglycosidase- $\mathrm{H}$ treatment, a glycosidase that selectively cleaves HM structures, which results in a loss of the $75-\mathrm{kDa}$ band only ${ }^{68}$; and immunoprecipitation with HMspecific lectins, followed by immunoblotting with anti-ICAM-1 antibody, only pulls down the $75-\mathrm{kD}$ a protein. ${ }^{68}$ Moreover, similar immunoprecipitation strategies applied to atherosclerotic tissue reveal the presence of an approximately $75-\mathrm{kDa}$ molecular weight ICAM-1 in vivo. ${ }^{68}$ The $75-\mathrm{kDa} \mathrm{N}$-glycoform observed on an immunoblot could simply reflect the pool of ICAM-1 present in the endoplasmic reticulum or Golgi that is in the process of becoming a complex $\mathrm{N}$-glycoform and before trafficking to the cell surface. Then, immunoprecipitation experiments of surface expressed ICAM-1 also reveal a 75-kDa band, and more recent studies using the proximity ligation assay show that an HM ICAM-1 is present on the surface of TNF- $\alpha$-activated endothelial cells. ${ }^{43,68}$ These data suggest that at least two different N-glycoforms of ICAM-1, HM and complex, may be present on the endothelial surface during inflammation.

Furthermore, when normalized to ICAM-1 levels, monocyte rolling and adhesion to HM ICAM-1 were approximately twofold to threefold higher compared with complex ICAM-1. ${ }^{68}$ That said, HM ICAM-1 abundance was approximately $10 \times$ lower than complex ICAM-1, which suggests that monocyte adhesion to HM ICAM-1 should still be largely mediated by complex ICAM-1. However, this does not exclude for potential differences in how HM or complex ICAM-1 engages with different leukocyte or monocyte subsets. A recent study addressed this question and demonstrated that HM ICAM-1 has a selective role in binding to $\mathrm{CD} 16^{+}$monocytes, but not CD16 ${ }^{-}$monocytes nor neutrophils. ${ }^{43}$ Blocking of HM structures on the endothelial surface abrogated $\mathrm{CD} 16^{+}$ rolling and adhesion, but not for $\mathrm{CD} 16^{-}$monocytes. ${ }^{43}$ Furthermore, a Cos- 1 cell system transfected with human ICAM-1 showed an increase in $\mathrm{CD} 16^{+}$monocyte adhesion, but not $\mathrm{CD}^{-} 6^{-}$monocytes, when ICAM-1 was expressed in a HM N-glycoform compared with a complex $\mathrm{N}$-glycoform. This effect too could be abrogated by lectin blocking of $\mathrm{HM}$ or hybrid $\mathrm{N}$-glycan structures. ${ }^{43}$ More important, the total levels of surface ICAM-1 did not change in these experiments; monocyte adhesion was attenuated only by changing the type of sugar on ICAM-1 or selectively blocking the sugar. 


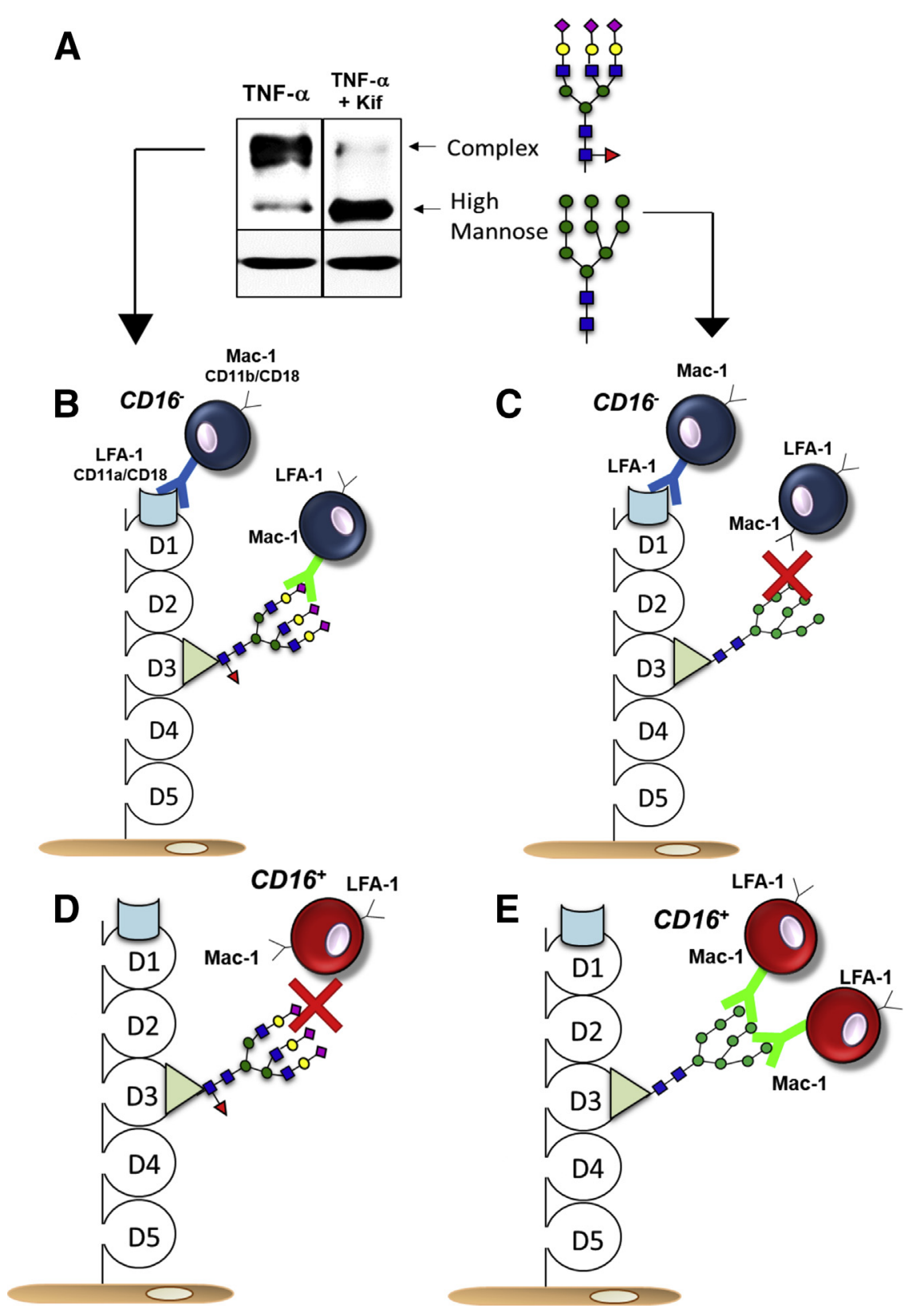

Figure 3 A: Representative Western blot analysis of intercellular adhesion molecule 1 (ICAM-1) from tumor necrosis factor (TNF)- $\alpha$ (10 $\mathrm{ng} / \mathrm{mL}, 4$ hours) treated human umbilical vein endothelial cells with or without kifunensine (Kif; class I $\alpha$-mannosidase inhibitor) pretreatment to demonstrate high-mannose ICAM-1 formation. B: $\mathrm{CD}_{16}{ }^{-}$monocytes adhere to ICAM-1 via the lymphocyte function-associated antigen 1 (LFA1) domain or macrophage-1 antigen (Mac-1) domain when the latter is modified with complex $\mathrm{N}$-glycans. C: $\mathrm{CD}_{16}{ }^{-}$monocytes do not adhere to the Mac-1 domain when it is modified with highmannose $\mathrm{N}$-glycans. D: $\mathrm{CD} 16^{+}$monocytes adhere to neither the LFA-1 domain of ICAM-1 nor the Mac-1 domain modified by complex N-glycans. E: CD16 ${ }^{-}$monocytes only bind to the Mac-1 domain when it is modified by high-mannose N-glycans.

There is precedent for suggesting that $\mathrm{N}$-glycans on ICAM-1 play a role in leukocyte adhesion. Seminal studies by the Springer laboratory mapped where on ICAM-1 leukocyte ligands bind and showed that LFA-1 binds domain 1 of ICAM-1, whereas macrophage-1 antigen (Mac1) binds domain $3 .^{77,78}$ Of note, domain 1 is devoid of $\mathrm{N}$-glycans, whereas domain 3 contains an $\mathrm{N}$-glycosylation site (Figure 3B). Furthering this point, Mac-1 binding to ICAM-1 can be regulated by altering glycosylation of the latter. ${ }^{78}$ Diamond et $\mathrm{al}^{78}$ demonstrated that Mac-1 binding to ICAM-1 was increased when ICAM-1 expressing cells were treated with deoxymannojiriycin, an $\boldsymbol{\alpha}$-mannosidase class I inhibitor that will cause the accumulation of HM structures on $\mathrm{N}$-glyocosylated proteins (Figure 2), similar to effects of kifunensine (Figuer 3A). LFA-1 binding to ICAM-1 was not affected by treatment with deoxymannojiriycin, and treatment with neuraminidase to remove sialic acid residues from ICAM-1 had no effect on binding on either LFA-1 nor Mac-1 to ICAM- $1{ }^{78}$ These data were one of the first to demonstrate a role for $\mathrm{N}$-glycans on endothelial cell adhesion molecules in controlling monocyte adhesion. The understanding of mechanisms regulating endothelial function during inflammation has evolved significantly, especially concerning how endothelial responses vary on the basis of the different types and rates of flow experienced in vivo. Indeed, many laboratories would argue that assessing endothelial biology under static conditions only is not sufficient, and experiments require integration of 
flow-dependent regulation. Illustrating this point are data that show leukocyte adhesion mechanisms to vascular cell adhesion molecule 1 , specifically the domain of vascular cell adhesion molecule 1 involved in adhesion, changes between static and flow conditions. ${ }^{79}$ Although many studies have investigated leukocyte adhesion under flow conditions, few have revisited the role of endothelial $\mathrm{N}$-glycans specifically. Recent work expands pioneering studies by Diamond et $\mathrm{al}^{78}$ and showed that, under flow, CD16 ${ }^{-}$monocyte rolling and adhesion were inhibited by blocking LFA-1 binding domain on ICAM-1 and, to a lesser extent, by blocking the Mac-1 domain. However, when all $\mathrm{N}$-glycans on the Mac-1 domain were HM, CD16 ${ }^{-}$cell adhesion became insensitive to Mac-1 domain blockade. In contrast, $\mathrm{CD} 16^{+}$monocyte adhesion showed little sensitivity to LFA-domain blocking, but was significantly attenuated by Mac-1 domain blocking. Taken together, these data support the model for how $\mathrm{CD} 16^{+}$and $\mathrm{CD} 16^{-}$ monocyte adhesion to endothelial cells is regulated by ICAM-1 N-glycoforms (Figure 3, B-E). Conceptually, sugars regulating leukocyte adhesion is not new mechanism of controlling leukocyte-endothelial interactions (eg, role of sialyl-Lewis X sugars on neutrophils and T cells). ${ }^{60}$ The model proposed in Figure 3 extends these concepts and identifies a role of sugars on endothelial adhesion molecules in controlling monocyte interactions in a subset-dependent manner. If domain 3 of ICAM-1 is modified by complex sugars, CD16 ${ }^{-}$monocytes will adhere via LFA- 1 and Mac1 , as seen (Figure 3B). However, if domain 3 of ICAM-1 is modified by high-mannose sugars, $\mathrm{CD} 16^{-}$monocytes will only adhere to the LFA-1 domain (Figure 3C). In contrast, $\mathrm{CD} 16^{+}$monocytes will not adhere to the LFA-1 domain of ICAM-1 nor to the Mac-1 domain if it is modified with complex sugars (Figure 3D), and they will only adhere to the Mac-1 domain if it is modified with high-mannose sugars (Figure 3E).

To reiterate, both $\mathrm{CD} 16^{-}$and $\mathrm{CD} 16^{+}$monocytes express similar levels of Mac- $1 .{ }^{33}$ How HM N-glycans on ICAM-1 endow selectivity for $\mathrm{Mac} 1$ on $\mathrm{CD}_{1} 6^{+}$monocytes then, but not on $\mathrm{CD}_{16}^{-}$monocytes, remains to be determined. Interestingly, CD16 itself may be involved. Within neutrophils, CD16 is linked to Mac-1 via sugar-based interactions; enzymatic digestion of neutrophil HM N-glycans on CD16 or addition of D-mannose, which competes with HM on CD16, abrogates interactions with Mac- $1 .^{80-84}$ These CD16-Mac-1 interactions are not seen, however, in monocytes, ${ }^{80,81,84}$ perhaps because of the fact that CD16A, the isoform found exclusively on monocytes, lacks an $\mathrm{N}$ glycosylation site found on CD16B, the isoform exclusively found on neutrophils. ${ }^{80}$ Thus, an HM N-glycan ligand for Mac-1 is provided by CD16B in neutrophils, which may prevent Mac-1 binding to HM structures on the endothelium. With $\mathrm{CD} 16^{+}$monocytes, this HM structure is absent, which hypothetically allows Mac-1 on these cells to bind to HM N-glycans from endothelial ICAM-1, and regulate, therefore, how $\mathrm{CD}^{+} 6^{+}$monocytes are recruited to endothelial cells over $\mathrm{CD}^{-} 6^{-}$monocytes or neutrophils. Further studies are needed to test this hypothesis, although notably, neutrophil adhesion was not found to be sensitive to the presence or absence of endothelial HM ICAM- $1 .{ }^{43}$

Finally, although the discussion of this review herein is focused on ICAM-1, it is worth noting that other endothelial adhesion molecules (eg, vascular cell adhesion molecule 1 and E-selectin) are also $\mathrm{N}$-glycosylated, but whether they can be formed as distinct $\mathrm{N}$-glycoforms during inflammation remains unclear. ${ }^{68,69}$

\section{Vascular Bed Dependence to Monocyte Recruitment and Re-Assessing Adhesion Molecule Therapeutics}

As mentioned earlier, endothelial-leukocyte adhesion is dependent on organ and type of leukocyte; for example, in lung capillaries, neutrophils have been shown to adhere more frequently in comparison to monocytes. ${ }^{51,85}$ Interestingly, although the exposure to TNF- $\alpha$ increases adhesion molecule expression in both aortic and pulmonary endothelial cells in vitro, formation of HM or hybrid $\mathrm{N}$-glycans on the cell surface was only observed with aortic endothelial cells, perhaps explaining why monocytes do not adhere as much as neutrophils to lung capillaries. ${ }^{11}$ This observation also suggests that differential formation of adhesion molecule $\mathrm{N}$-glycoforms is one mechanism that underlies heterogeneous responses to inflammation by endothelial cells from different vascular beds. ${ }^{1,9,11,86}$ The potential for endothelial surface $\mathrm{N}$-glycan signatures varying in different vascular beds, or as a function of disease within a given bed, supports the concept of an N-glycan zip code that directs which monocyte subset is recruited and to which site of inflammation. This idea is similar to that proposed by others. ${ }^{10,87}$ For example, Renkonen et $\mathrm{al}^{10}$ used three different antibodies against distinct glycans on L-selectin (sialyl-Lewis X, sulfated sialyl-Lewis X, and sulfated lactosamine) and measured their expression levels on the endothelium across several inflammatory diseases, including thyroiditis, vasculitis, myocarditis, and colitis. When compared with noninflamed tissue, the inflamed endothelium contained higher amounts of these sugars, with the relative expression of each glycan varying by disease. The investigators assigned each disease a three-number code based on the positive staining for each glycan tested, deeming it an organ-specific zip code, and suggested this code regulates L-selectin-dependent lymphocyte homing. ${ }^{10}$

Understanding that different N-glycoforms of ICAM-1 may mediate recruitment of distinct monocyte subsets has implications for therapeutics also. Previous studies have tested whether inhibiting monocyte-endothelial interactions protects against inflammatory diseases. In mice and other animal models, inhibition of adhesion molecules, such as ICAM-1, via knockout or antibody-based functional blocking, abrogates atherosclerosis. ${ }^{88-90}$ However, anti-ICAM-1 
blocking antibodies have not worked in humans. Enlimomab, a monoclonal antibody against ICAM-1, in fact increased mortality and adverse events in stroke patients. Data from other trials in kidney allograft rejection, multiple myeloma, or Crohn disease show similar lack of efficacy by anti-ICAM-1 therapeutics, ${ }^{91-93}$ suggesting that broad inhibition of ICAM1 is not a plausible therapeutic, likely reflecting the multiple, good and bad, roles of ICAM-1 across the innate immunity to inflammatory disease spectrum. Recent positive data from the Canakinumab Anti-Inflammatory Thrombosis Outcomes Study (CANTOS), showing that IL-1 $\beta$ antagonism improved cardiovascular disease outcomes, suggest that antiinflammatory strategies can be efficacious. ${ }^{94-96}$ This review hypothesizes that developing approaches that inhibit only HM ICAM-1 dependent effects, rather than all ICAM-1, may be a safer approach and one that selectively attenuates proinflammatory monocyte recruitment to sites of endothelial dysfunction. Currently, no HM glycoform-specific therapies for inflammation exist. Interestingly, however, recent studies have shown that dietary mannose can slow tumor growth in mice, and improve metabolism, resulting in the attenuation of obesity onset. ${ }^{97,98}$ The effects of mannose on monocyteendothelial interactions were not directly tested in these studies; however, an intriguing possibility is that dietary mannose competes with endothelial HM structures, ${ }^{67}$ attenuating monocytic inflammation.

Finally, although the discussion of endothelial heterogeneity and monocyte adhesion herein has focused on human disease, the proposed paradigms may be applicable to animal models as well, which may provide experimental systems to delineate detailed mechanisms by which N-glycans regulate atherogenic inflammation. First, mouse monocyte subsets that are more or less inflammatory have been described; proinflammatory Ly6 $\mathrm{C}^{\text {hi }}$ monocyte subsets are associated with more advanced atherosclerosis and inflammation. $^{26,99,100}$ Similarly, heterogeneity across mouse endothelial beds with respect to responses to inflammation, lectin staining, surface adhesion molecules, and leukocyte adhesion has been reported also. ${ }^{101-103}$ That said, not all human and mouse proteins are $\mathrm{N}$-glycosylated to the same extent, nor at the same sites. Human ICAM- 1 contains $8 \mathrm{~N}$ glycan sites, whereas mouse ICAM-1 contains 10, for example, and whether similar changes in high mannose $\mathrm{N}$ glycans occurs is not known. These differences underline the importance of comparing and validating mouse with human models; and potential differences in N-glycans may have contributed to the relative poor translation of data generated in murine models to human disease and therapeutics.

\section{Gaps in Knowledge and Final Thoughts}

The proposed model does not imply that ICAM-1 harbors either HM or complex N-glycans. ICAM-1 contains eight $\mathrm{N}$-glycosylation sites, and each site can be differentially modified with any variety of $\mathrm{N}$-glycan structures (HM, hybrid, or complex). Given that each of these sites can be modified by a different sugar, the possibilities of structures increasing logarithmically with each site were added. Lau et $\mathrm{al}^{104}$ calculated that a protein with one $\mathrm{N}$-glycosylation site can have up to 14 different $\mathrm{N}$-glycoforms, whereas a protein with eight $\mathrm{N}$-glycosylation sites, such as ICAM-1, may have $>200,000$ different N-glycoforms. Referring to HM ICAM-1 herein means that there are HM epitopes on ICAM-1 that are responsible for monocyte adhesion, which are likely to be in domain 3 . Exactly which of the eight $\mathrm{N}$ glycan sites on ICAM-1 harbor HM structures, and how formation of N-glycans at these site(s) is regulated, remains unclear. Another key question is how the formation of HM structures is regulated. Given the linear pathway for Nglycan biosynthesis (Figure 2), inhibition of $\alpha$-mannosidases is one possible mechanism. Consistent with this idea, TNF- $\alpha$ inhibits $\alpha$-mannosidase activity. ${ }^{11,68}$ Understanding how this occurs will inform on mechanisms endothelial cells use to regulate $\mathrm{N}$-glycoforms during inflammation and perhaps yield additional targets for therapeutic targeting. Finally, the impact that binding to different N-glycoforms of ICAM-1 has on monocytic function beyond adhesion (eg, migration and differentiation) is another area that remains to be studied. Understanding these changes may further shed light on how monocyte functions are regulated during inflammation.

This review highlights how endothelial $\mathrm{N}$-glycosylation of surface adhesion molecules, regulation of this process, and formation of HM ICAM-1 specifically may regulate monocyte trafficking. We suggest that HM ICAM-1 is a critical mediator of proinflammatory monocyte adhesion and propose that glyco-specific therapeutics should be considered to selectively modulate chronic inflammatory diseases.

\section{References}

1. Aird WC: Phenotypic heterogeneity of the endothelium, II: representative vascular beds. Circ Res 2007, 100:174-190

2. Cejkova S, Kralova-Lesna I, Poledne R: Monocyte adhesion to the endothelium is an initial stage of atherosclerosis development. Cor Vasa 2015, 58:e419-e425

3. Esper RJ, Nordaby RA, Vilarino JO, Paragano A, Cacharron JL, Machado RA: Endothelial dysfunction: a comprehensive appraisal. Cardiovasc Diabetol 2006, 5:4

4. Devaux B, Scholz D, Hirche A, Klovekorn WP, Schaper J: Upregulation of cell adhesion molecules and the presence of low grade inflammation in human chronic heart failure. Eur Heart J 1997, 18: 470-479

5. Rondaij MG, Bierings R, Kragt A, van Mourik JA, Voorberg J: Dynamics and plasticity of Weibel-Palade bodies in endothelial cells. Arterioscler Thromb Vasc Biol 2006, 26:1002-1007

6. Haverslag R, Pasterkamp G, Hoefer I: Targeting adhesion molecules in cardiovascular disorders. Cardiovasc Hematol Disord Drug Targets 2008, 8:252-260

7. Boyette LB, Macedo C, Hadi K, Elinoff BD, Walters JT, Ramaswami B, Chalasani G, Taboas JM, Lakkis FG, Metes DM: 
Phenotype, function, and differentiation potential of human monocyte subsets. PLoS One 2017, 12:e0176460

8. Swirski FK, Weissleder R, Pittet MJ: Heterogeneous in vivo behavior of monocyte subsets in atherosclerosis. Arterioscler Thromb Vasc Biol 2009, 29:1424-1432

9. Aird WC: Endothelial cell heterogeneity. Cold Spring Harb Perspect Med 2012, 2:a006429

10. Renkonen J, Tynninen O, Hayry P, Paavonen T, Renkonen R: Glycosylation might provide endothelial zip codes for organ-specific leukocyte traffic into inflammatory sites. Am J Pathol 2002, 161: $543-550$

11. Scott DW, Vallejo MO, Patel RP: Heterogenic endothelial responses to inflammation: role for differentital $\mathrm{N}$-glycosylation and vascular bed of origin. J Am Heart Assoc 2013, 2:e000263

12. de Leoz ML, Young LJ, An HJ, Kronewitter SR, Kim J, Miyamoto S, Borowsky AD, Chew HK, Lebrilla CB: High-mannose glycans are elevated during breast cancer progression. Mol Cell Proteomics 2011, 10. M110.002717

13. van Furth R, Raeburn JA, van Zwet TL: Characteristics of human mononuclear phagocytes. Blood 1979, 54:485-500

14. Ziegler-Heitbrock L: Blood monocytes and their subsets: established features and open questions. Front Immunol 2015, 6:423

15. Idzkowska E, Eljaszewicz A, Miklasz P, Musial WJ, Tycinska AM, Moniuszko M: The role of different monocyte subsets in the pathogenesis of atherosclerosis and acute coronary syndromes. Scand J Immunol 2015, 82:163-173

16. Cros J, Cagnard N, Woollard K, Patey N, Zhang SY, Senechal B, Puel A, Biswas SK, Moshous D, Picard C, Jais JP, D’Cruz D, Casanova JL, Trouillet C, Geissmann F: Human CD14dim monocytes patrol and sense nucleic acids and viruses via TLR7 and TLR8 receptors. Immunity 2010, 33:375-386

17. Smedman C, Ernemar T, Gudmundsdotter L, Gille-Johnson P, Somell A, Nihlmark K, Gardlund B, Andersson J, Paulie S: FluoroSpot analysis of TLR-activated monocytes reveals several distinct cytokine-secreting subpopulations. Scand J Immunol 2012, 75: 249-258

18. Zawada AM, Rogacev KS, Rotter B, Winter P, Marell RR, Fliser D, Heine GH: SuperSAGE evidence for CD14++CD16+ monocytes as a third monocyte subset. Blood 2011, 118:e50-e61

19. Auffray C, Fogg D, Garfa M, Elain G, Join-Lambert O, Kayal S, Sarnacki S, Cumano A, Lauvau G, Geissmann F: Monitoring of blood vessels and tissues by a population of monocytes with patrolling behavior. Science 2007, 317:666-670

20. Wong KL, Tai JJ, Wong WC, Han H, Sem X, Yeap WH, Kourilsky P, Wong SC: Gene expression profiling reveals the defining features of the classical, intermediate, and nonclassical human monocyte subsets. Blood 2011, 118:e16-e31

21. Rossol M, Kraus S, Pierer M, Baerwald C, Wagner U: The CD14(bright) CD16+ monocyte subset is expanded in rheumatoid arthritis and promotes expansion of the Th17 cell population. Arthritis Rheum 2012, 64:671-677

22. Belge KU, Dayyani F, Horelt A, Siedlar M, Frankenberger M, Frankenberger B, Espevik T, Ziegler-Heitbrock L: The proinflammatory $\mathrm{CD} 14+\mathrm{CD} 16+\mathrm{DR}++$ monocytes are a major source of TNF. J Immunol 2002, 168:3536-3542

23. Skrzeczynska-Moncznik J, Bzowska M, Loseke S, GrageGriebenow E, Zembala M, Pryjma J: Peripheral blood CD14 high CD16+ monocytes are main producers of IL-10. Scand J Immunol 2008, 67:152-159

24. Shantsila E, Wrigley B, Tapp L, Apostolakis S, Montoro-Garcia S, Drayson MT, Lip GY: Immunophenotypic characterization of human monocyte subsets: possible implications for cardiovascular disease pathophysiology. J Thromb Haemost 2011, 9:1056-1066

25. Nahrendorf M: Myeloid cell contributions to cardiovascular health and disease. Nat Med 2018, 24:711-720

26. Randolph GJ: The fate of monocytes in atherosclerosis. J Thromb Haemost 2009, 7 Suppl 1:28-30
27. Babaev VR, Bobryshev YV, Sukhova GK, Kasantseva IA: Monocyte/macrophage accumulation and smooth muscle cell phenotypes in early atherosclerotic lesions of human aorta. Atherosclerosis 1993, 100:237-248

28. Bobryshev YV: Monocyte recruitment and foam cell formation in atherosclerosis. Micron 2006, 37:208-222

29. Bobryshev YV, Lord RS: Ultrastructural recognition of cells with dendritic cell morphology in human aortic intima: contacting interactions of vascular dendritic cells in athero-resistant and atheroprone areas of the normal aorta. Arch Histol Cytol 1995, 58:307-322

30. Libby P: Changing concepts of atherogenesis. J Intern Med 2000, 247:349-358

31. Lusis AJ: Atherosclerosis. Nature 2000, 407:233-241

32. Rogacev KS, Cremers B, Zawada AM, Seiler S, Binder N, Ege P, Grosse-Dunker G, Heisel I, Hornof F, Jeken J, Rebling NM, Ulrich C, Scheller B, Bohm M, Fliser D, Heine GH: CD14++CD16+ monocytes independently predict cardiovascular events: a cohort study of 951 patients referred for elective coronary angiography. J Am Coll Cardiol 2012, 60:1512-1520

33. Wildgruber M, Aschenbrenner T, Wendorff H, Czubba M, Glinzer A, Haller B, Schiemann M, Zimmermann A, Berger H, Eckstein HH, Meier R, Wohlgemuth WA, Libby P, Zernecke A: The "intermediate" CD14(++)CD16(+) monocyte subset increases in severe peripheral artery disease in humans. Sci Rep 2016, 6:39483

34. Heine GH, Ulrich C, Seibert E, Seiler S, Marell J, Reichart B, Krause M, Schlitt A, Kohler H, Girndt M: CD14(++)CD16+ monocytes but not total monocyte numbers predict cardiovascular events in dialysis patients. Kidney Int 2008, 73:622-629

35. Merino A, Buendia P, Martin-Malo A, Aljama P, Ramirez R, Carracedo J: Senescent CD14+CD16+ monocytes exhibit proinflammatory and proatherosclerotic activity. J Immunol 2011, 186: $1809-1815$

36. Berg KE, Ljungcrantz I, Andersson L, Bryngelsson C, Hedblad B, Fredrikson GN, Nilsson J, Bjorkbacka H: Elevated CD14++CD16monocytes predict cardiovascular events. Circ Cardiovasc Genet 2012, 5:122-131

37. Zawada AM, Fell LH, Untersteller K, Seiler S, Rogacev KS, Fliser D, Ziegler-Heitbrock L, Heine GH: Comparison of two different strategies for human monocyte subsets gating within the large-scale prospective CARE FOR HOMe Study. Cytometry A 2015, 87:750-758

38. Weber C, Shantsila E, Hristov M, Caligiuri G, Guzik T, Heine GH, Hoefer IE, Monaco C, Peter K, Rainger E, Siegbahn A, Steffens S, Wojta J, Lip GY: Role and analysis of monocyte subsets in cardiovascular disease: joint consensus document of the European Society of Cardiology (ESC) Working Groups "Atherosclerosis \& Vascular Biology" and "Thrombosis." Thromb Haemost 2016, 116:626-637

39. Wong KL, Yeap WH, Tai JJY, Ong SM, Dang TM, Wong SC: The three human monocyte subsets: implications for health and disease. Immunol Res 2012, 53:41-57

40. Ziegler-Heitbrock L: The CD14+ CD16+ blood monocytes: their role in infection and inflammation. J Leukoc Biol 2007, 81:584-592

41. Starikova EA, Lebedeva AM, Freidlin IS: $[C D 14++$ CD16- and CD14+CD16+ human monocytes adhesion to endothelial cells] Russian. Tsitologiia 2010, 52:380-383

42. Aspinall AI, Curbishley SM, Lalor PF, Weston CJ, Blahova M, Liaskou E, Adams RM, Holt AP, Adams DH: CX(3)CR1 and vascular adhesion protein-1-dependent recruitment of $\mathrm{CD} 16(+)$ monocytes across human liver sinusoidal endothelium. Hepatology 2010, 51:2030-2039

43. Regal-McDonald K, Xu B, Barnes JW, Patel RP: High-mannose intercellular adhesion molecule-1 (ICAM-1) enhances CD16+ monocyte adhesion to the endothelium. Am J Physiol Heart Circ Physiol 2019, 317:H1028-H1038

44. Bevilacqua MP: Endothelial-leukocyte adhesion molecules. Annu Rev Immunol 1993, 11:767-804

45. Carlos TM, Harlan JM: Leukocyte-endothelial adhesion molecules. Blood 1994, 84:2068-2101 
46. Faruqi RM, DiCorleto PE: Mechanisms of monocyte recruitment and accumulation. Br Heart J 1993, 69:S19-S29

47. Lim K, Hyun YM, Lambert-Emo K, Topham DJ, Kim M: Visualization of integrin Mac-1 in vivo. J Immunol Methods 2015, 426: $120-127$

48. Deniset JF, Kubes P: Intravital imaging of myeloid cells: inflammatory migration and resident patrolling. Microbiol Spectr 2016, 4. MCHD-0042-2016

49. Libby P, Nahrendorf M, Swirski FK: Monocyte heterogeneity in cardiovascular disease. Semin Immunopathol 2013, 35:553-562

50. Hilgendorf I, Swirski FK: Making a difference: monocyte heterogeneity in cardiovascular disease. Curr Atheroscler Rep 2012, 14: 450-459

51. Leick M, Azcutia V, Newton G, Luscinskas FW: Leukocyte recruitment in inflammation: basic concepts and new mechanistic insights based on new models and microscopic imaging technologies. Cell Tissue Res 2014, 355:647-656

52. Gerhardt T, Ley $\mathrm{K}$ : Monocyte trafficking across the vessel wall. Cardiovasc Res 2015, 107:321-330

53. Mestas J, Ley K: Monocyte-endothelial cell interactions in the development of atherosclerosis. Trends Cardiovasc Med 2008, 18: $228-232$

54. Bombeli T, Schwartz BR, Harlan JM: Adhesion of activated platelets to endothelial cells: evidence for a GPIIbIIIa-dependent bridging mechanism and novel roles for endothelial intercellular adhesion molecule 1 (ICAM-1), alphavbeta3 integrin, and GPIbalpha. J Exp Med 1998, 187:329-339

55. Ed Rainger G, Chimen M, Harrison MJ, Yates CM, Harrison P, Watson SP, Lordkipanidze M, Nash GB: The role of platelets in the recruitment of leukocytes during vascular disease. Platelets 2015, 26 : $507-520$

56. Ancuta P, Rao R, Moses A, Mehle A, Shaw SK, Luscinskas FW, Gabuzda D: Fractalkine preferentially mediates arrest and migration of CD16+ monocytes. J Exp Med 2003, 197:1701-1707

57. Shimaoka M, Xiao T, Liu JH, Yang Y, Dong Y, Jun CD, McCormack A, Zhang R, Joachimiak A, Takagi J, Wang JH, Springer TA: Structures of the alpha L I domain and its complex with ICAM-1 reveal a shape-shifting pathway for integrin regulation. Cell 2003, 112:99-111

58. Snapp KR, Ding H, Atkins K, Warnke R, Luscinskas FW, Kansas GS: A novel P-selectin glycoprotein ligand-1 monoclonal antibody recognizes an epitope within the tyrosine sulfate motif of human PSGL-1 and blocks recognition of both P- and L-selectin. Blood 1998, 91:154-164

59. Hickey MJ, Forster M, Mitchell D, Kaur J, De Caigny C, Kubes P: Lselectin facilitates emigration and extravascular locomotion of leukocytes during acute inflammatory responses in vivo. J Immunol 2000, 165:7164-7170

60. Rodgers SD, Camphausen RT, Hammer DA: Sialyl Lewis(x)mediated, PSGL-1-independent rolling adhesion on P-selectin. Biophys J 2000, 79:694-706

61. Dennis JW, Granovsky M, Warren CE: Protein glycosylation in development and disease. Bioessays 1999, 21:412-421

62. Tian E, Ten Hagen KG: Recent insights into the biological roles of mucin-type O-glycosylation. Glycoconj J 2009, 26:325-334

63. Stanley P, Schachter H, Taniguchi N: N-glycans. Edited by Varki A, Cummings RD, Esko JD, Freeze HH, Stanley P, Bertozzi CR, Hart GW, Etzler ME. In Essentials of Glycobiology. ed 2. New York, NY: Cold Spring Harbor, 2009

64. Roth J, Zuber C: Quality control of glycoprotein folding and ERAD: the role of N-glycan handling, EDEM1 and OS-9. Histochem Cell Biol 2017, 147:269-284

65. Rudd PM, Elliott T, Cresswell P, Wilson IA, Dwek RA: Glycosylation and the immune system. Science 2001, 291:2370-2376

66. Wong MY, Chen K, Antonopoulos A, Kasper BT, Dewal MB Taylor RJ, Whittaker CA, Hein PP, Dell A, Genereux JC, Haslam SM, Mahal LK, Shoulders MD: XBP1s activation can globally remodel N-glycan structure distribution patterns. Proc Natl Acad Sci U S A 2018, 115:E10089-E10098

67. Chacko BK, Scott D, Chandler RT, Patel RP: Endothelial surface Nglycans mediate monocyte adhesion and are targets for anti-inflammatory effects of peroxisome proliferator-activated receptor Y ligands. J Biol Chem 2011, 286:38738-38747

68. Scott D, Dunn T, Ballestas M, Litovsky S, Patel RP: Identification of a high-mannose ICAM-1 glycoform: effects of ICAM-1 hypoglycosylation on monocyte adhesion and outside in signaling. Am J Physiol Cell Physiol 2013, 305:C228-C237

69. Scott DW, Chen J, Chacko BK, Traylor JG, Orr AW, Patel RP: Role for endothelial $\mathrm{N}$-glycan mannose residues in monocyte recruitment during atherogenesis. Arterioscler Thromb Vasc Biol 2012, 32: e $51-\mathrm{e} 59$

70. Chen H, Deng Z, Huang C, Wu H, Zhao X, Li Y: Mass spectrometric profiling reveals association of $\mathrm{N}$-glycan patterns with epithelial ovarian cancer progression. Tumour Biol 2017, 39. 1010428317716249

71. Stowell SR, Ju T, Cummings RD: Protein glycosylation in cancer. Annu Rev Pathol 2015, 10:473-510

72. Talabnin K, Talabnin C, Ishihara M, Azadi P: Increased expression of the high-mannose M6N2 and NeuAc3H3N3M3N2F triantennary N-glycans in cholangiocarcinoma. Oncol Lett 2018 , 15:1030-1036

73. Chui D, Sellakumar G, Green R, Sutton-Smith M, McQuistan T, Marek K, Morris H, Dell A, Marth J: Genetic remodeling of protein glycosylation in vivo induces autoimmune disease. Proc Natl Acad Sci U S A 2001, 98:1142-1147

74. Staunton DE, Marlin SD, Stratowa C, Dustin ML, Springer TA: Primary structure of ICAM-1 demonstrates interaction between members of the immunoglobulin and integrin supergene families. Cell 1988, 52:925-933

75. Liu G, Place AT, Chen Z, Brovkovych VM, Vogel SM, Muller WA, Skidgel RA, Malik AB, Minshall RD: ICAM-1-activated Src and eNOS signaling increase endothelial cell surface PECAM-1 adhesivity and neutrophil transmigration. Blood 2012, 120:1942-1952

76. Tani M, Kamata Y, Deushi M, Osaka M, Yoshida M: 7 Ketocholesterol enhances leukocyte adhesion to endothelial cells via p38MAPK pathway. PLoS One 2018, 13:e0200499

77. Diamond MS, Staunton DE, de Fougerolles AR, Stacker SA, GarciaAguilar J, Hibbs ML, Springer TA: ICAM-1 (CD54): a counterreceptor for Mac-1 (CD11b/CD18). J Cell Biol 1990, 111: 3129-3139

78. Diamond MS, Staunton DE, Marlin SD, Springer TA: Binding of the integrin Mac-1 (CD11b/CD18) to the third immunoglobulin-like domain of ICAM-1 (CD54) and its regulation by glycosylation. Cell 1991, 65:961-971

79. Abe Y, Ballantyne CM, Smith CW: Functions of domain 1 and 4 of vascular cell adhesion molecule-1 in alpha4 integrin-dependent adhesion under static and flow conditions are differentially regulated. J Immunol 1996, 157:5061-5069

80. Edberg JC, Kimberly RP: Cell type-specific glycoforms of Fc gamma RIIIa (CD16): differential ligand binding. J Immunol 1997, 159: 3849-3857

81. Kimberly RP, Tappe NJ, Merriam LT, Redecha PB, Edberg JC, Schwartzman S, Valinsky JE: Carbohydrates on human Fc gamma receptors: interdependence of the classical $\operatorname{IgG}$ and nonclassical lectin-binding sites on human Fc gamma RIII expressed on neutrophils. J Immunol 1989, 142:3923-3930

82. Preynat-Seauve O, Villiers CL, Jourdan G, Richard MJ, Plumas J, Favier A, Marche PN, Favrot MC: An interaction between CD16 and CR3 enhances $\mathrm{iC} 3 \mathrm{~b}$ binding to CR3 but is lost during differentiation of monocytes into dendritic cells. Eur J Immunol 2004, 34:147-155

83. Xia Y, Borland G, Huang J, Mizukami IF, Petty HR, Todd RF 3rd, Ross GD: Function of the lectin domain of Mac-1/complement receptor type $3(\mathrm{CD} 11 \mathrm{~b} / \mathrm{CD} 18)$ in regulating neutrophil adhesion. J Immunol 2002, 169:6417-6426 
84. Zhou M, Todd RF 3rd, van de Winkel JG, Petty HR: Cocapping of the leukoadhesin molecules complement receptor type 3 and lymphocyte function-associated antigen-1 with Fc gamma receptor III on human neutrophils: possible role of lectin-like interactions. J Immunol 1993, 150:3030-3041

85. Kreisel D, Nava RG, Li W, Zinselmeyer BH, Wang B, Lai J, Pless R, Gelman AE, Krupnick AS, Miller MJ: In vivo two-photon imaging reveals monocyte-dependent neutrophil extravasation during pulmonary inflammation. Proc Natl Acad Sci U S A 2010, 107:18073-18078

86. Aird WC: Phenotypic heterogeneity of the endothelium, I: structure, function, and mechanisms. Circ Res 2007, 100:158-173

87. Thorpe PE, Ran S: Mapping zip codes in human vasculature. Pharmacogenomics J 2002, 2:205-206

88. Bourdillon MC, Poston RN, Covacho C, Chignier E, Bricca G, McGregor JL: ICAM-1 deficiency reduces atherosclerotic lesions in double-knockout mice (ApoE(-/-)/ICAM-1(-/-)) fed a fat or a chow diet. Arterioscler Thromb Vasc Biol 2000, 20:2630-2635

89. Argenbright LW, Letts LG, Rothlein R: Monoclonal antibodies to the leukocyte membrane CD18 glycoprotein complex and to intercellular adhesion molecule-1 inhibit leukocyte-endothelial adhesion in rabbits. J Leukoc Biol 1991, 49:253-257

90. Collins RG, Velji R, Guevara NV, Hicks MJ, Chan L, Beaudet AL: P-selectin or intercellular adhesion molecule (ICAM)-1 deficiency substantially protects against atherosclerosis in apolipoprotein Edeficient mice. J Exp Med 2000, 191:189-194

91. Salmela K, Wramner L, Ekberg H, Hauser I, Bentdal O, Lins LE, Isoniemi H, Backman L, Persson N, Neumayer HH, Jorgensen PF, Spieker C, Hendry B, Nicholls A, Kirste G, Hasche G: A randomized multicenter trial of the anti-ICAM-1 monoclonal antibody (enlimomab) for the prevention of acute rejection and delayed onset of graft function in cadaveric renal transplantation: a report of the European Anti-ICAM-1 Renal Transplant Study Group. Transplantation 1999, 67:729-736

92. Wichert S, Juliusson G, Johansson A, Sonesson E, Teige I, Wickenberg AT, Frendeus B, Korsgren M, Hansson M: A single-arm, open-label, phase 2 clinical trial evaluating disease response following treatment with BI-505, a human anti-intercellular adhesion molecule-1 monoclonal antibody, in patients with smoldering multiple myeloma. PLoS One 2017, 12:e0171205

93. Yacyshyn B, Chey WY, Wedel MK, Yu RZ, Paul D, Chuang E: A randomized, double-masked, placebo-controlled study of alicaforsen, an antisense inhibitor of intercellular adhesion molecule 1 , for the treatment of subjects with active Crohn's disease. Clin Gastroenterol Hepatol 2007, 5:215-220
94. Everett BM, Cornel JH, Lainscak M, Anker SD, Abbate A, Thuren T, Libby P, Glynn RJ, Ridker PM: Anti-inflammatory therapy with canakinumab for the prevention of hospitalization for heart failure. Circulation 2019, 139:1289-1299

95. Ridker PM, MacFadyen JG, Thuren T, Everett BM, Libby P, Glynn RJ, Group CT: Effect of interleukin-1beta inhibition with canakinumab on incident lung cancer in patients with atherosclerosis: exploratory results from a randomised, double-blind, placebocontrolled trial. Lancet 2017, 390:1833-1842

96. Kosmas CE, Silverio D, Sourlas A, Montan PD, Guzman E, Garcia MJ: Anti-inflammatory therapy for cardiovascular disease. Ann Transl Med 2019, 7:147

97. Sharma V, Smolin J, Nayak J, Ayala JE, Scott DA, Peterson SN, Freeze HH: Mannose alters gut microbiome, prevents diet-induced obesity, and improves host metabolism. Cell Rep 2018, 24:3087-3098

98. Gonzalez PS, O'Prey J, Cardaci S, Barthet VJA, Sakamaki JI, Beaumatin F, Roseweir A, Gay DM, Mackay G, Malviya G, Kania E, Ritchie S, Baudot AD, Zunino B, Mrowinska A, Nixon C, Ennis D, Hoyle A, Millan D, McNeish IA, Sansom OJ, Edwards J, Ryan KM: Mannose impairs tumour growth and enhances chemotherapy. Nature 2018, 563:719-723

99. Rahman K, Vengrenyuk Y, Ramsey SA, Vila NR, Girgis NM, Liu J, Gusarova V, Gromada J, Weinstock A, Moore KJ, Loke P, Fisher EA: Inflammatory Ly6Chi monocytes and their conversion to M2 macrophages drive atherosclerosis regression. J Clin Invest 2017, 127:2904-2915

100. Woollard KJ, Geissmann F: Monocytes in atherosclerosis: subsets and functions. Nat Rev Cardiol 2010, 7:77-86

101. Gumkowski F, Kaminska G, Kaminski M, Morrissey LW, Auerbach R: Heterogeneity of mouse vascular endothelium: in vitro studies of lymphatic, large blood vessel and microvascular endothelial cells. Blood Vessels 1987, 24:11-23

102. Murphy TJ, Thurston G, Ezaki T, McDonald DM: Endothelial cell heterogeneity in venules of mouse airways induced by polarized inflammatory stimulus. Am J Pathol 1999, 155:93-103

103. Lim YC, Garcia-Cardena G, Allport JR, Zervoglos M, Connolly AJ, Gimbrone MA Jr, Luscinskas FW: Heterogeneity of endothelial cells from different organ sites in T-cell subset recruitment. Am J Pathol 2003, 162:1591-1601

104. Lau KS, Partridge EA, Grigorian A, Silvescu CI, Reinhold VN, Demetriou M, Dennis JW: Complex N-glycan number and degree of branching cooperate to regulate cell proliferation and differentiation. Cell 2007, 129:123-134 